\title{
The Prayer Savant
}

\author{
MARK JARMAN
}

On a yellow legal pad

she wrote her rows of names

with a big carpenter's pencil

and made a sunny garden

of the block graphite letters.

Her parents brought people to her

one at a time through the day.

If you came to her with a name

and she caught something about you

with her cockeyed mask of attention

she would write your name down too.

And if you left her, feeling poorly,

I have heard from witnesses,

later on in the day

you might feel a sudden lightening.

She sat in her childhood bedroom

with Burl Ives on her record player

singing "Big Rock Candy Mountain"

and praying through her list, praying through every name and the names from the day before and the day before that and before and never forgot a name.

She remembered no one's face but she never forgot a name.

Her parents had given her this condition and occupation.

It was how they lived with themselves and how their prayer was answered. 